\title{
Insect visitors to avocado flowers in the Bay of Plenty, New Zealand
}

\author{
S.F.J. Read ${ }^{1}$, B.G. Howlett ${ }^{1}$, L.K. Jesson ${ }^{3}$ and D.E. Pattemore ${ }^{2}$ \\ ${ }^{1}$ The New Zealand Institute for Plant \& Food Research Limited, Private Bag 4704, \\ Christchurch Mail Centre, Christchurch 8140, New Zealand \\ ${ }^{2}$ The New Zealand Institute of Plant \& Food Research Ltd, Private Bag 3230 \\ Waikato Mail Centre, Hamilton 3240, New Zealand \\ ${ }^{3}$ The New Zealand Institute of Plant \& Food Research Ltd, Private Bag 1401 \\ Havelock North 4157, New Zealand \\ Corresponding author: sam.read@plantandfood.co.nz
}

\begin{abstract}
Insect pollination is key to ensuring adequate fruit yields within avocado orchards. Various bee and non-bee insect species have been considered as potential pollinators of avocado worldwide, but in New Zealand there has been little research into which insect species visit avocado flowers. In the Bay of Plenty, an important avocado production area, flower visitor abundance and diversity data were obtained by conducting observational surveys in four orchards in November 2015. Honey bees were the dominant flower visitors in all orchards surveyed, representing $92.9 \%$ of all insects recorded, but there was high variation in numbers among sites. Other common insects observed included the beetle, Zorion guttigerum (3.4\%), and bumblebees Bombus spp. (1.6\%). A better understanding of the interaction between honey bee stocking rates and flower visitor abundances within orchards could assist in improving pollination recommendations.
\end{abstract}

Keywords insect pollinators, pollinator diversity, pollination abundance, diurnal patterns, honey bee, survey, avocado pollination, flower visitor abundance, Persea americana.

\section{INTRODUCTION}

Avocado (Persea americana), native to Central America and Mexico, is an evergreen subtropical fruiting tree grown commercially in the warmer regions of northern New Zealand (Evans et al. 2010). Insect pollination has been shown to be essential for fruit production (Ish-Am \& Lahav 2011). In its native environment, a wide range of insect taxa are considered to be pollinators including bees, wasps (Hymenoptera) and flies (Diptera) (Perez-Balam et al. 2012), but honey bees (Apis mellifera) are considered the principal pollinators in many commercial orchards (Gazit 1976; Ish-Am \& Eisikowitch 1993; Evans et al. 2011).

Individual avocado flowers typically open twice, first as a female and secondly as a male the following day (Ish-Am \& Lahav 2011), and the timing of this flowering varies depending on cultivar type (“A" \& "B") (Gazit 1976). In New Zealand, 'Hass' (type A), is the dominant commercial fruiting cultivar (Evans et al. 2011). Growers generally plant type B cultivars as 
pollinisers within the orchard to increase the opportunities for cross pollination by ensuring male polliniser flowers are open when 'Hass' female flowers are open (Gazit 1976; Evans et al. 2011). Pollinators are required to move pollen from male flowers to 'Hass' female flowers on adjacent trees.

The Bay of Plenty is an important avocadoproduction area in New Zealand. A study of one orchard there found that honey bees represented 97.4\% of all flower visits (Evans et al. 2011). In contrast, only $37.9 \%$ of the visitors were honey bees at two orchards in Australia (Hampton, Queensland and Port Macquarie, New South Wales). The majority (49.7\%) were hover flies and the remainder included other flies and native bees (Evans et al. 2011). In New Zealand, the placement of four to ten hives/ha has been recommended for avocado pollination (Avocado Industry Council Ltd 2006).

Identifying which pollinator species visit avocado flowers is important for understanding the potential contribution each species could make to pollination through different management strategies. Because of limited published information on the visitors to avocado flowers in New Zealand, the aim of this study was to gather more knowledge on the abundance of flower visitors across avocado orchards located in the Bay of Plenty.

\section{MATERIALS AND METHODS}

Pollinating insects at four orchards located within a twenty kilometre radius of Katikati, Bay of Plenty $(-37.552,175.917)$ were studied on three days 3, 5 and 6 November 2015. The size and tree density of each orchard were: Orchard 1; 2.0 ha, 68 trees/ha, Orchard 2; 0.6 ha, 110 trees/ ha, Orchard 3; 1.6 ha, 53 trees/ha and Orchard 4; 2.0 ha, 59 trees/ha. For each orchard, surveys were conducted three times per day between 10:00-11:00 hr, 12:00-13:00 hr and 14:00-15:00 hr. Four trained observers were employed to conduct surveys (one per orchard), and where rotated between orchards across days. We did not conduct surveys across consecutive days due to rainfall on 4 November. On the survey days, we recorded ambient temperature using a ThermoHydro recorder, and light intensity (irradiance) measured as Watts (W)/ $\mathrm{m}^{2}$ towards the sun using a Daystar meter. We only surveyed on days of fine weather with wind speed below $15 \mathrm{~km} / \mathrm{h}$ (measured using a Silva Windwatch). Orchard bee hive stocking rates varied considerably, with Orchard 1 having 4 hives per hectare and, Orchards 2 and 4 having 3 and 5.2 hives per hectare respectively. Orchard 3 had no honey bees placed in it, and it was the only certified organic orchard.

Each day, insect surveys were conducted across 18 'Hass' and 3 polliniser trees per orchard using a standardised technique across all orchards. Three sets of trees were chosen in each orchard block, one set each at opposing corners of the block and the third set in the centre. Six 'Hass' trees were marked within each set with three trees located in one row and three in an adjacent row. Every second tree was chosen as a survey tree in each row and we alternated survey trees between rows. Therefore, in set 1, (a corner set), chosen trees in row 1 were tree 1 (corner tree), 3 and 5 ; in row 2 : 2, 4 and 6. A polliniser tree closest to each set of 'Hass' trees was also included in the survey.

The flowering phase of each tree was recorded. Male phase flowers were distinguished by the presence of extended stamens and anthers (usually dehiscing pollen), while for female phase flowers, non-dehiscing anthers were positioned prostate against the petals.

For each 'Hass' tree, we surveyed all open flowers at a height between 0.5 and $2 \mathrm{~m}$ above ground. The observer then counted flowervisiting insects around half the circumference $\left(180^{\circ}\right)$ of each tree on flowers located from the outer canopy to the trunk of the tree, over a period of $120 \pm 15$ secs per tree. We surveyed the same sides of each tree within a row and the adjacent $180^{\circ}$ of trees in the second row. Therefore, for each set, the side of each tree faced into the same row. We used the same survey technique for polliniser trees except surveyed the full circumference $\left(360^{\circ}\right)$. We aim to publish further details of the survey techniques in a separate document. 
The numbers or species of insects did not differ greatly between 'Hass' and polliniser trees (honey bees represented $93.0 \%$ in 'Hass' and $92.8 \%$ in pollinisers) so combined counts were used for most analyses (unless explicitly stated). A mixed-effects generalised linear model with a Poisson error distribution using the $\mathrm{R}$ package lme4 (Bates et al. 2015) was used to test whether or not hive-stocking rates within orchards influenced honey bee counts. Date and stocking rate were considered continuous fixed variables, and the grouping structure of orchard (as counts at an orchard over days will be influenced by counts on the previous survey day) was included. A polynomial curve was fitted to data to account for possible non-linearity over time, and to assess the relative importance of date and stocking rate by comparing nested models using loglikelihood estimates.

\section{RESULTS}

A total of 3674 insects from 18 species within 10 families were recorded visiting avocado flowers in this study (Table 1). Of these, 92.9\% were honey bees. $1.6 \%$ bumblebees (Bombus terrestris and B. ruderatus) and 3.4\% were flowervisiting longhorn beetles (Zorion guttigerum; Cerambycidae), (Table 1). All other species combined represented $2.0 \%$ of flower visitors observed.

Honey bees dominated in all orchards across all three days surveyed. The minimum percentage total count that honey bees represented was $55.9 \%$ in Orchard 2 on 5 November 2015. At this date, the second most abundant species $(38.5 \%$ of all counts) was the beetle Zorion guttigerum. The maximum proportion of honey bees in counts in an orchard on one day was $99.1 \%$ at Orchard 1 (5 November 2015).

Male flowers were much more frequently open than female flowers during the survey periods. Across the three days, Orchard 1 had 92.8\% male flowers, Orchard 2 had 95.1\%, Orchard 3 had 94.2\% and Orchard 4 had $88.4 \%$ male flowers. Therefore, the likelihood of insects visiting male flowers was much greater. Insect preferences for male/female flowers were not studied.
Across the 36 individual surveys (orchard $\times$ day $\times$ time), the ambient temperature ranged between 14 and $26^{\circ} \mathrm{C}$, and light intensity between 180 and $1350 \mathrm{~W} / \mathrm{m}^{2}$. Average temperature across survey days and orchards were not very variable although average light intensity was more so (Table 2). Numbers of honey bees varied across days within each orchard, more than doubling in number for two orchards from 4 Nov and 6 Nov. (Table 2). Orchard 4 had consistently the highest total honey bee counts and Orchard 2 the lowest (Table 1).

Generalised linear mixed models suggested that the bee-hive stocking rate at an orchard and the date of measurement both strongly influenced honey bee abundance. The best overall model included the following fixed effects parameters: stocking rate; a polynomial term for date; and the interaction between the two. The model assumed that (following terminology from Zuur 2009):

$\mathrm{Y}_{i j} \sim \operatorname{Poisson}\left(\mu_{i j}\right)$

$\log \left(\mu_{i j}\right)=a+\beta 1 \times$ StockingRate $_{i j}+\beta 2 \times$ Date $_{i j}+$ $\beta 3 \times$ Date $_{i j}+\beta 4 \times$ Stocking rate $\times$ Date $_{i j}+a_{j}$

$a_{j} \sim \operatorname{Normal}\left(0, \sigma_{a}^{2}\right)$

where $Y_{i j}$ is the number of insects counted in transect $i$ in orchard $j$, and is assumed to be Poisson distributed, with a mean and variance of $\mu Y_{i j}$ and a logarithmic link between the mean of $Y_{i j}$ and the predictor function A random intercept $a_{i}$ for each orchard was included and it was assumed that the random intercept is normally distributed with a mean of 0 and variance $\sigma_{a}^{2}$. The results from this model suggested that the total honey bee counts varied among orchards with different hive stocking rates over the three assessment dates. Removal of the interaction term from the model resulted in a significantly poorer model fit $(\mathrm{P}<0.001)$ and log-likelihood scores $(-73.04$ cf. $-91.50)$. As expected, generally the total number of honey bees counted increased as the hive stocking rate increased (with the exception of Orchard 3 which had no hives). Interestingly, many more honeybees were present on 'Hass' 
Table 1 Combined total numbers of insects recorded on 'Hass' and polliniser avocado cultivars in each of four Bay of Plenty orchards (1-4) over the three surveyed days (3, 5 and 6 November 2015).

\begin{tabular}{lllllll}
\hline Order, family, species & \multicolumn{5}{c}{ Insect Count } \\
\hline & Orchard & 1 & 2 & 3 & 4 & Total \\
\cline { 2 - 6 } Hymenoptera & & & & & &
\end{tabular}

Apidae

$$
\begin{aligned}
& \text { Apis mellifera } \\
& \text { Bombus terrestris } \\
& \text { Bombus ruderatus }
\end{aligned}
$$

$\begin{array}{rrrrr}841 & 187 & 512 & 1874 & 3414 \\ 11 & 0 & 4 & 44 & 59 \\ 0 & 0 & 0 & 1 & 1\end{array}$

Halictidae

$$
\text { Lasioglossum spp. }
$$

Other Hymenoptera

$\begin{array}{rrrrr}1 & 0 & 0 & 0 & 1 \\ 0 & 0 & 5 & 11 & 16\end{array}$

\section{Diptera}

Calliphoridae

Calliphora stygia

$\begin{array}{lllll}5 & 5 & 5 & 5 & 20\end{array}$

Calliphora vicina

$\begin{array}{lllll}0 & 0 & 0 & 4 & 4\end{array}$

Lucilia sericata

Other Calliphidae spp.

100001

$1 \quad 0 \quad 0 \quad 001$

Syrphidae

Melangyna
movaezelandiae

Melanostoma fasciatum

$\begin{array}{lllll}0 & 4 & 2 & 4 & 10\end{array}$

Eristalis tenax

$\begin{array}{llll}0 & 1 & 1 & 0\end{array}$

Other Syrphidae spp.

$\begin{array}{lllll}0 & 0 & 0 & 1 & 1\end{array}$

Tachinidae

Tachinidae spp.

$\begin{array}{lllll}0 & 1 & 1 & 0 & 2\end{array}$

Stratiomyidae

Exaireta spinigera

$\begin{array}{lllll}0 & 0 & 1 & 1 & 2\end{array}$

Bibionidae

Dilophus nigrostigma

$\begin{array}{llll}0 & 0 & 1 & 0\end{array}$

1

\section{Coleoptera}

Cerambycidae

$$
\text { Zorion guttigerum }
$$

\section{Hemiptera}

Myridae

Myridae spp.

$\begin{array}{llll}0 & 0 & 0 & 4\end{array}$ 
Table 2 Average temperature $\left({ }^{\circ} \mathrm{C}\right)$, average light intensity $\left(\mathrm{W} / \mathrm{m}^{2}\right)$ and total counts of honey bees observed across three survey days.

\begin{tabular}{rrrr}
\hline Variable & Orchard & \multicolumn{3}{c}{ Date } \\
& 3-Nov-15 & 5-Nov-15 & 6-Nov-15 \\
\hline Temperature & & & \\
1 & 21.7 & 20.0 & 17.3 \\
2 & 22.7 & 18.8 & 18.6 \\
3 & 17.9 & 16.3 & 17.6 \\
4 & 21.6 & 18.8 & 19.1 \\
\hline Light Intensity & & & \\
1 & 512.7 & 895.0 & 1065.0 \\
2 & 339.0 & 861.0 & 1005.3 \\
3 & 339.3 & 912.3 & 1001.8 \\
4 & 331.7 & 896.9 & 1067.3 \\
\hline Honey bee count & & & \\
1 & 150 & 356 & 335 \\
2 & 49 & 66 & 72 \\
3 & 182 & 124 & 206 \\
4 & 409 & 644 & 821 \\
\hline
\end{tabular}

trees (at least $83.4 \%$ of all honey bees counted within the orchard) than on the pollinisers in Orchards 1, 2 and 4 while fewer honey bees were present on 'Hass' trees $(45.7 \%$ of all honey bees counted) in Orchard 3.

\section{DISCUSSION}

Avocado requires insect pollination to maximise yields and the findings of this study highlights the likely importance of honey bees as pollinators within the surveyed orchards. Although the efficiency of the various flower visiting species was not assessed, the generally low abundance of non-honey bee flower visitors (relative to honey bees) suggested their relative minor role in pollination across most of the surveyed days. A trend was observed suggesting honey bee abundance might be correlated with hive stocking rates although there were too few orchards to test the significance of the correlation statistically. The organic orchard did not contain any bee hives and recorded generally lower counts of insect flower visitors than Orchards 1 and 4 but higher counts than Orchard 2 across all survey days. However, honey bee abundances also varied by a factor of two in two orchards across the survey days. Both temperature and light intensity are correlated with honey bee abundances in other crops (Howlett et al 2013a), and, in our study, increasing light intensity aligned with increasing honey bee abundances and could be a factor influencing abundances between days. Further assessment of the pollinator efficiency of honey bees, factors influencing their abundances within orchards and the potential benefits of stocking orchards with hives will provide useful guidelines for growers to evaluate whether pollinator numbers are adequate to maximise pollination.

Counts of other flower visitors were much lower than for honey bees but at least 18 flower visiting species from 10 families of bees, flies and beetles were observed. The native flower longhorn beetle Zorion guttigerum, was the only species that represented a high proportion of non-bee flower visitors across survey days (38.5\% of flower visits across a single day in Orchard 2). Previous studies have suggested that non-bee pollinator species can be abundant in avocado orchards in other countries, such as Australia (Evans et al. 2011), Mexico (PerezBalam et al. 2012), and Central America (IshAm \& Eisikowitch 1993), and that these have the potential to play a significant role in pollination (Perez-Balam et al. 2012; Garibaldi et al. 2013). In New Zealand, non-honey bee flower visitors can contribute to the pollination of other crops such as pak choi (Rader et al. 2009), onion (Howlett et al. 2017b), and carrot (Howlett 2012), and may also contribute to pollination of kiwifruit (Macfarlane \& Ferguson 1984; Howlett et al. 2017a) and plum (McBrydie et al. 2017).

Factors that affect the presence of wild pollinators include the presence of native vegetation, suitable nesting or sheltering locations and pesticides (Howlett et al. 2013b). However, large numbers of wild pollinators visiting flowers were not observed even in the certified organic orchard (Orchard 3). The reasons why visitor numbers were low in a crop 
that can attract diverse wild pollinator species was not explored in this study. Boosting numbers of wild pollinators, in combination with managed honey bees, could potentially increase crop yields (Garibaldi et al. 2013).

This survey primarily observed insects visiting male 'Hass' flowers, as low numbers of female 'Hass' flowers were recorded during our survey periods. Female flowering occurs for a short period daily ( 3 to 4 hours) and the timing of their opening is dependent on air temperature (Gazit 1976). Our experimental design of three sample periods each day largely missed the peak female flowering period. Further study is needed to assess whether these patterns of flower visitor diversity and abundance are similar during peak female flowering. Temperature (particularly overnight minima) substantially influences the timing of female flower opening in avocado so peak activity of specific pollinating species may not match with optimal pollination times. Encouraging a diversity of insects that can be active under variable weather conditions and over extended periods of the day (Howlett et al. 2017a) may ensure pollinators are active at the highly variable times that female flowers are open.

\section{ACKNOWLEDGEMENTS}

We thank Lisa Evans, Rachael L'helgoualc'h, Alexandre Benoist, Simon Cornut and Justyna Giejsztowt for assistance in surveying and/ or editing. We would also like to thank New Zealand Avocado (NZ Avocado Growers Assn Inc., Avocado Industry Council Ltd), Phillip West and Álvaro Vidiella for their support and information, and the growers for kindly allowing access to their orchards. This work was supported through funding from the Ministry of Business, Innovation and Employment (C11X1309).

\section{REFERENCES}

Avocado Industry Council Ltd 2006. Grower and beekeeper guide: Avocado pollination - best practice guidelines. Avocado Industry Council Ltd, Tauranga, New Zealand.
Bates D, Maechler M, Bolker B, Walker S 2015. Fitting Linear Mixed-Effects Models Using lme4. Journal of Statistical Software, 67: 1-48. doi:10.18637/jss.v067.i01.

Evans L, Goodwin R, McBrydie H 2010. Factors affecting 'Hass' avocado (Persea americana) fruit set in New Zealand. New Zealand Plant Protection 63: 214-218.

Evans LJ, Goodwin RM, Howlett BG 2011. The role of insect pollinators in avocado (Persea americana) pollination in New Zealand and Australia. In Proceedings VII World Avocado Congress. p. 7.

Garibaldi LA, Steffan-Dewenter I, Winfree R, Aizen MA, Bommarco R, Cunningham SA, Kremen C, Carvalheiro LG, Harder LD, Afik $\mathrm{O}$ and others 2013. Wild pollinators enhance fruit set of crops regardless of honey-bee abundance. Science 339: 1608-1611.

Gazit S 1976. Pollination and Fruit Set of Avocado. Proceedings of the First International Tropical Fruit Short Course: The Avocado. Sauls JW, Phillips RL, and Jackson LK eds. Gainesville: Fruit Crops Dept., Florida Cooperative. Extension Service. Institute of Food and Agricultural Sciences, University of Florida. Pp. 88-92.

Howlett BG 2012. Hybrid carrot seed crop pollination by the fly Calliphora vicina (Diptera: Calliphoridae). Journal of Applied Entomology 136: 421-430.

Howlett BG, Read SFJ, Jesson LK, Benoist A, Evans LE, Pattemore DE 2017a. Diurnal insect visitation patterns to 'Hayward' kiwifruit flowers in New Zealand. New Zealand Plant Protection 70: 52-57.

Howlett B, Butler R, Nelson W, Donovan B 2013a. Impact of climate change on crop pollinator activity in New Zealand. MPI Technical Paper No: 2013/30, Ministry for Primary Industries. 45 pp. www.mpi.govt.nz/ document-vault/4101. (accessed 10 January 2017). 45 pp.

Howlett BG, Davidson MM, Mathers D, Pyke NB 2013. Hedgerow plants to support crop pollination and pest management. Weta: 46: 3-12. 
Howlett BG, Evans LJ, Pattemore DE, Nelson WR 2017b. Stigmatic pollen delivery by flies and bees: Methods comparing multiple species within a pollinator community. Basic and Applied Ecology 19: 19-25.

Ish-Am G, Eisikowitch D 1993. The behaviour of honey bees (Apis mellifera) visiting avocado (Persea americana) flowers and their contribution to its pollination. Journal of Apicultural Research 32: 175-186.

Ish-Am G, Lahav E 2011. Evidence for a major role of honeybees (Apis mellifera) rather than wind during avocado (Persea americana Mill.) pollination. Journal of Horticultural Science and Biotechnology 86: 589-594.

Macfarlane RP, Ferguson AM 1984. Kiwifruit pollination: a survey of the insect pollinators in New Zealand. Fifth International Symposium on Pollination, Versailles. Sept. 1983, Les Colloques de I'INRA.
McBrydie HM, Howlett BG, Pattemore DE 2017. Relative abundance and movement of flower visitors within 'Black Doris' plum orchards in Hawke's Bay, New Zealand New Zealand Plant Protection 70: 58-62.

Perez-Balam J, Quezada-Euan JJ, Alfaro-Bates R, Medina S, McKendrick L, Soro A, Paxton RJ 2012. The contribution of honey bees, flies and wasps to avocado (Persea americana) pollination in southern Mexico. Journal of Pollination Ecology 8: 42-47.

Rader R, Howlett BG, Cunningham SA, Westcott DA, Newstrom-Lloyd LE, Walker MK, Teulon DAJ, Edwards W 2009. Alternative pollinator taxa are equally efficient but not as effective as the honeybee in a mass flowering crop. Journal of Applied Ecology 46: 1080-1087.

Zuur AF, Ieno EN, Walker NJ, Saveliev AA, Smith GM 2009. Mixed Effects Models and Extensions in Ecology with R (1 ed.). Springer, New York. 